\title{
IMPACTO DE UMA INTERVENÇÃO PEDAGÓGICA NA LEITURA DE MUNDO DA CRIANCA SOBRE SER NEGRA
}

\author{
Germana Ponce de Leon Ramírez \\ luciane Weber Baia HeEs \\ Centro Universitário Adventista de São Paulo (UNASP), São Paulo, \\ São Paulo, Brasil
}

\begin{abstract}
Resumo: O objetivo desta pesquisa é analisar o impacto de uma intervenção pedagógica na leitura de mundo da criança acerca do ser negro(a). Este estudo caracteriza-se por ser qualitativo e de natureza aplicada. A leitura de mundo relacionada com a criança negra foi avaliada através das respostas de pré e pós-testes, obtidas pelo questionário de escala facial. A criança aprende e começa a ler o mundo antes mesmo de ler as letras. Isso se desdobra em uma gama de interpretações cujos valores se constroem a partir das experiências que as crianças negras vivenciam lendo o mundo em um contexto cujas ações discriminatórias no espaço escolar são presentes. Identifica-se que as intervenções lúdicas possibilitam reflexão e mudanças, auxiliando na erradicação de atitudes preconceituosas e estereótipos negativos que existem acerca do ser negro.
\end{abstract}

Palavras-chave: Estereótipo. Criança negra. Visão de mundo. Questionário de escala facial. 
INTRODUÇÃO

De acordo com Mello (2000), a família se torna para a criança negra uma unidade social que desenvolve múltiplos papéis fundamentais para o crescimento psicológico do indivíduo, mostrando as diferenças sociais e culturais, como também é uma organização de apoio, proteção, limites e socialização. Entretanto, alguns fatores interferem na construção da identidade da criança, como a propagação do preconceito, atos discriminatórios e o uso de estereótipos negativos.

No contexto escolar, o negro está sujeito a um complexo mecanismo manipulador da maneira como a criança faz a leitura de mundo e isso reflete no processo de construção de sua própria identidade, interferindo na formação da criança, tanto em relação a sua aprendizagem quanto na formação de sua identidade cultural.

Desse modo, este trabalho se desdobra em três partes: a primeira refere-se à relação do desenvolvimento da criança com a forma como ela lê o mundo. Já a segunda parte traz à tona os caminhos metodológicos percorridos nesta pesquisa. Em seguida, apresentam-se a análise e as discussões dos dados coletados em campo. Por fim, tem-se as considerações finais, que evidenciam alguns elementos que podem contribuir com a mudança na forma como a criança enxerga o mundo, no sentido de proporcionar uma consciência de valorização da diversidade étnica e de autovalorização.

\section{A CRIANÇA NEGRA E O MUNDO A SER INTERPRETADO}

A concepção de infância, ao longo do contexto histórico, é algo estudado por saberes diversos que trazem em suas essências imagens sociais distintas da criança, cujas concepções têm como perspectiva a visão dos adultos. Há ainda um silêncio histórico acerca da infância devido à ausência de problematização sobre essa categoria. Mas aqui a criança será entendida na concepção que se estabelece no Ocidente desde o século XVIII, de que ela é diferente do adulto e que necessita ser tratada com cuidados específicos (ANDRADE, 2010).

Os seis primeiros anos de uma criança são muito importantes para sua vida adulta, nesse período acontece o desenvolvimento da inteligência, da afetividade e das relações sociais. Esse desenvolvimento exige uma maturação do sistema nervoso e um ambiente favorável para isso, pois, no desenvolvimento humano, o processo de sua organização passa por fases psicossexuais e do desenvolvimento cognitivo, o que vai favorecer o desenvolvimento social da criança (MIRANDA; MARTINS, 2009). 
É na família que se inicia a socialização, preparando o indivíduo para a etapa seguinte, a socialização secundária, que deverá acontecer no convívio em ambientes como escola, igreja, grupos de amigos, entre outros. Esse envolvimento e essa atuação em contextos sociais, como também a convivência da criança com o mundo adulto, podem favorecer o surgimento de julgamentos raciais. Por conseguinte, atitudes de caráter negativo podem surgir, principalmente em se tratando de uma sociedade que tem uma representatividade negativa de grupos sociais como negros, indígenas, entre outros (GOMES, 1994; MUNANGA; GOMES, 2016).

No contexto de desenvolvimento infantil, a criança aprende a ler o mundo e, como diz Paulo Freire, ela começa a ler o mundo antes mesmo de ler as letras. Essa leitura de mundo é associada a uma gama de interpretações cujos valores estão se formando a partir das experiências que as crianças vão tendo. A percepção dos elementos que compõem o espaço vivido é essencial para a compreensão do seu papel social.

A educação recebida pela criança, de acordo com pesquisadores como Piaget, Erikson, Berger e Luckman, se torna um elemento fundamental para o desenvolvimento humano do sujeito social e, nessa concepção, a escola e a família são bases para a formação e socialização do indivíduo. As pré-escolas e creches, destinadas a atender as crianças, formalizam um processo de aprendizado que teve início na família, dando prosseguimento nas relações com a sociedade. Destarte, a escola se torna também responsável pela aprendizagem da vida social, mas a família ainda é o laço mais forte de socialização da criança.

A criança absorve as experiências vividas ao seu redor, baseia-se em como ela interpreta esses estímulos vivenciados em seu ambiente, dando mais atenção às atitudes do que as palavras. Assim, a família e a escola têm um papel social importante no desenvolvimento do caráter e das competências humanas. Por meio dessa relação, a criança tem grandes chances de se tornar um adulto socialmente comprometido se forem atendidas as necessidades emocionais, físicas, intelectuais e sociais (VALLE; GUZZO, 2004; TELES, 2008).

É importante destacar que, no processo de desenvolvimento social, a leitura não se limita à decifração do código escrito, mas "[...] tal ação se inscreve como um ato de consciência política, porque tornam visíveis as relações e lutas simbólicas que acontecem entre as classes sociais para verem naturalizados seus bens e valores culturais" (BORGES JR; FREIRE; MACEDO, 2015, p. 305). Esses valores culturais perpassam a consciência de valorização ou não do ser negro. Assim, nessa conjuntura, na leitura do espaço que faz 
parte do processo de ler o mundo podem estar implícitos preconceitos que interferem negativamente na leitura da autopercepção da criança negra.

A sociedade determina um modelo de categorias e, ainda, cataloga os indivíduos conforme os atributos considerados comuns e naturais. $A$ sociedade estabelece, também, qual a categoria que as pessoas devem pertencer, de acordo com seus atributos, criando um padrão externo ao indivíduo e, muitas vezes, trazendo estigmas sociais. Desse modo, a sociedade tem a capacidade de limitação e delimitação da ação do sujeito estigmatizado, estabelecendo e determinando os efeitos ruins que podem representar. Quando se torna mais visível a marca, menos possibilidade o indivíduo tem de reverter a imagem anteriormente construída pelo padrão social (GOFFMAN, 2015; MELO, 2000).

Borges Jr, Freire e Macedo (2015) asseveram que uma educação que valoriza seus sujeitos sociais como executores de seus papéis coloca em xeque a reprodução da ideologia dominante e isso colabora para a compreensão do mundo no sentido de construir referenciais capazes de modificar as condições materiais e históricas vigentes sob uma perspectiva dominante. Em contrapartida, e sob uma perspectiva de Paulo Freire, a leitura proporciona enxergar politicamente e, por conseguinte, perceber a vida como um processo biográfico e coletivo.

Para tanto, a percepção da vida é o ato de ler o mundo e, nesse processo, as ações discriminatórias existentes no espaço escolar, dentre outros, têm contribuído no sentido de limitar a leitura de mundo sob uma perspectiva etnocêntrica e isso tem chegado às crianças sem que elas tenham consciência disso. Destarte, a existência das atitudes discriminatórias e preconceituosas no ambiente escolar é algo real e negar tais atitudes, ao invés de acabar com tal ato violento, incentiva sua existência e sua perpetuidade. Vale salientar que tais preconceitos e estereótipos, vivenciados cotidianamente, podem gerar traumas para a vida toda (MIRANDA; MARTINS, 2009).

Outro ponto importante no que tange o espaço escolar é a promulgação da Lei 10.639/03, instituindo a obrigatoriedade do ensino de História da África e da Cultura Afro-brasileira e direcionando o sistema educacional no Brasil a inserir a discussão acerca das questões de cidadania e democracia. A referida lei foi promulgada tendo em vista a preocupação em orientar o educando a conhecer as características étnicas do Brasil, visando contribuir para a valorização da diversidade étnica no país e objetivando a reflexão e a conscientização, no sentido de agir e reagir às ações discriminatórias e favorecer a formação da cidadania. 
Segundo as diretrizes curriculares nacionais para educação das relações étnico-raciais, a educação é um dos principais mecanismos de transformação de um povo. E a escola tem como papel, na forma de democracia, compreender e valorizar o indivíduo em processo de aprendizagem. A escola ainda é responsável em estimular a formação de valores, hábitos e comportamentos que apreciem as diferentes características dos grupos humanos, abrindo caminho para o crescimento da cidadania de um povo (BRASIL, 2004).

Para Gomes (2002), a escola é vista não só como um local onde ocorrem o aprendizado e os saberes escolares, mas, também, um local de construção de valores, assim como preconceitos. Nessa perspectiva, a escola pode ser apontada como um local onde acontecem situações que podem interferir na construção da identidade negra. A maneira como é trabalhada a cultura do negro dentro da escola pode valorizar ou estigmatizar a sua identidade.

Nesse sentido, Cavalleiro (2012, p.99) assevera que a "[...] escola tem perpetuado desigualdades de tratamento e minado efetivas oportunidades igualitárias a todas as crianças. Sabe-se que a transformação da sociedade não é tarefa apenas da educação, mas espera-se que ela acompanhe as transformações sociais e as mudanças históricas".

Monteiro (2011) ressalta que a criança negra sofre constantemente várias situações de constrangimento no ambiente escolar. São situações que ferem a autoestima e a sua imagem, criando um clima complicado para se conviver e tornando muito difícil a construção de identidade positiva.

Para Bento (2011), a criança adquire o conceito sobre etnia ouvindo conversas dos adultos a sua volta. Esses conceitos são manifestados pelas crianças a princípio no plano verbal e, a posteriori, quando mais velhas, tendem a transformá-los em atitudes. Seguindo essa análise, o papel da família e dos educadores é muito importante para a formação da identidade desse indivíduo. Ligada à identidade de si, está também a construção gradativa da personalidade que é formada no decorrer da existência do ser humano, existindo toda uma complexidade no conceito sobre identidade.

A leitura que a criança faz do mundo em que vive é também responsabilidade de como a sociedade a recebe, a ensina, a faz enxergar esse mundo. A família, a escola, a mídia e os espaços sociais em geral ensinam uma leitura da percepção de mundo que lhe é imposta por uma ideologia etnocêntrica dominante consciente e inconscientemente. Nessa dimensão, está a construção da identidade da criança negra que, comumente, é pautada sob uma perspectiva negativa. 
Munanga (2012) diz que a construção da identidade envolve fatores históricos, psicológicos, linguísticos, culturais, político-ideológicos. Nesse processo de construção da identidade, há uma tomada de consciência das diferenças existentes entre os humanos. Todavia, a propagação do preconceito, atos discriminatórios e o uso de estereótipos interferem na construção da identidade do indivíduo. Como ocorre com todos os indivíduos, o negro está sujeito a esse complexo mecanismo construtor, estabelecido e manipulador de identidade.

Teles (2008) ressalta que a criança não nasce com sentimento negativo ou de inferioridade, mas essas significações são construídas ao longo de um contexto histórico calcado em estereótipos negativos intrínsecos à sociedade em que se vive. Assim, a escola, nesse processo de construção da identidade, exerce um papel importante porque reafirma os elementos culturais de uma sociedade, enriquecendo o desenvolvimento da criança e a sua inserção social, cumprindo o papel socializador e, por conseguinte, favorecendo o desenvolvimento da identidade.

No processo de construção da identidade, a escola pode interferir na leitura de mundo das crianças de uma forma geral e, por conseguinte, das crianças negras. Assim, planejou-se um projeto pedagógico para as séries iniciais com o objetivo de provocar uma reação por parte das crianças, no que tange a reflexão acerca da valorização do ser negro(a).

\section{Percurso metodológico da PESQUisa}

Trata-se de uma pesquisa qualitativa de natureza aplicada, realizada em uma instituição pública de ensino, situada na cidade de Engenheiro Coelho - SP. A pesquisa foi realizada entre os meses de outubro e novembro de 2017.

Para a aplicação da intervenção, foram utilizadas algumas estratégias que atendem ao processo de construção de conceitos pela criança. O primeiro momento da intervenção foi feito através de uma música, na qual tanto a letra quanto a melodia contemplam a intenção do projeto, a saber: fazer a criança negra se sentir valorizada. Utilizou-se desse recurso porque a música, ao longo da história, sempre"desempenhou, um importante papel no desenvolvimento do ser humano, seja no aspecto religioso, moral e social, o que contribuiu para a aquisição de hábitos e valores indispensáveis ao exercício de sua cidadania" (LOUREIRO, 2010, p. 5). No segundo momento da intervenção, foi trabalhada com as crianças uma história cantada e representada por personagens caracterizados; essa história também visa à valorização da criança negra.

A intervenção alcançou crianças do ensino fundamental I de uma instituição pública de ensino, de ambos os sexos, com faixa etária entre $4 \mathrm{e}$ 
10 anos, perfazendo um total de 800 participantes (alunos) ao todo. Como eram muitas crianças para uma única apresentação, foram feitas quatro sessões, com aproximadamente 200 crianças em cada uma. Dias (2012) corrobora neste sentido ao dizer que o trabalho pedagógico deve fazer uso de elementos que ajudem na construção da identidade étnica da criança, de maneira positiva, considerando que sua identidade não pode ser imposta. Para a construção desse processo, é preciso que o educador não tenha receio de abordar o tema. O lúdico é uma ferramenta que favorece a construção de conceitos relacionados com a diversidade étnica e racial. É importante trabalhar as diferenças como sendo algo positivo para a criança, utilizando elementos que a ajudem no processo de construção de sua identidade cultural de modo positivo.

A leitura de mundo relacionada à criança negra foi avaliada através das respostas de pré-testes e pós-testes, reguladas pela escala hedônica facial. $\mathrm{O}$ delineamento das intervenções foi realizado em duas etapas, os dados foram colhidos antes (pré-teste) e depois (pós-teste) da intervenção aplicada. O prée o pós-testes são uma ferramenta que possibilita a avaliação de intervenções e permite determinar se houve diferença no grupo em relação a alguma variável de interesse após uma intervenção. Com a medida do pré-teste, podemos comparar se a intervenção foi significativa com a medida do pós-teste.

Segundo Aaker et al. (2001), a elaboração de um questionário é considerada uma "arte imperfeita", pois não existem procedimentos exatos que assegurem que seus objetivos sejam alcançados adequadamente. Para o autor, fatores como bom senso e experiência do pesquisador evitam vários tipos de erros. Entretanto, existe uma sequência de etapas lógicas que devemos seguir para desenvolver um questionário:

1. planejar;

2. formular as perguntas;

3. definir o texto, a ordem das perguntas e o aspecto visual do questionário;

4. testar o questionário, utilizando uma pequena amostra;

5. se necessário, corrigir o problema e fazer novo pré-teste.

Pretende-se, nesta pesquisa, identificar se houve mudanças no modo de olhar a criança negra após a intervenção realizada. Portanto, escolheram-se apenas duas perguntas, simples e objetivas, por se tratar de crianças pequenas e por atenderem o que as pesquisadoras buscavam identificar. Foi realizado um pré-teste do questionário e os resultados descartaram a necessidade de reformulação. 
Para atender aos critérios de usabilidade, como legibilidade e concisão, foram utilizados ícones em forma de carinhas, objetivando facilitar a compreensão, garantindo o preenchimento independente do nível de escolaridade e aumentando o desempenho ao responder o questionário (RAMALHO, 1997; BONATE, 2000).

Os ícones apresentados referem-se a uma escala que abrange os conceitos de:

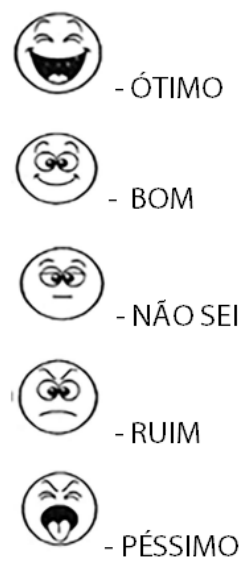

Para a elaboração desses critérios, partiu-se da escala de Likert, que apresenta cinco proposições, entre as quais o respondente deve selecionar uma, podendo ser: concorda totalmente, concorda, sem opinião, discorda, discorda totalmente. Depois é efetuada uma quantificação das respostas, que varia de modo consecutivo: $+2,+1,0,-1,-2$ ou utilizando pontuações de 1 a 5 . Portanto, criou-se uma escala que advém da escala de Likert com os mesmos objetivos, mas num formato diferente, pois baseia-se em carinhas, apresentando nas extremidades duas proposições contrárias.

Deu-se o nome para essa escala de Questionário de Escala Fácil e optou-se por fazer uso desse tipo de questionário, por acreditar ser mais indicada para os alunos do ensino fundamental nível I, facilitando a compreensão, e por conter expressões faciais lúdicas (rostinhos) que representam o grau de aceitação, de acordo com o tema envolvido, conforme a Figura 1 e a Figura 2. Nesse caso específico, tem a finalidade de representar o grau de aceitação referente às diferenças raciais após a intervenção promovida na escola. 
Figura 1 - Questionáriode Escala Facial

\begin{tabular}{|c|c|c|c|c|}
\hline \multicolumn{5}{|c|}{ SER NEGRO É: } \\
\hline 6 & (60) & (60) & (6) & (ิ) \\
\hline ÓTIMO & BOM & NÁOSEI & RUIM & PÉSSIMO \\
\hline \multicolumn{5}{|c|}{ TER UM AMIGO NEGRO: } \\
\hline 6 & (90) & (60) & (6) & (2) \\
\hline ÓTIMO & BOM & NÄOSEI & RUIM & PÉSSIMO \\
\hline
\end{tabular}

Fonte: Elaborado pelas pesquisadoras (2017).

Figura 2 - Questionário de Escala Facial

\begin{tabular}{|c|c|c|c|c|}
\hline \multicolumn{5}{|c|}{ SER NEGRO É: } \\
\hline 6 & (60) & (30) & (60) & (6) \\
\hline о́тімо & BOM & NĀO SEI & RUIM & PÉSSIMO \\
\hline \multicolumn{5}{|c|}{ TER UM AMIGO NEGRO: } \\
\hline 6 & (90) & (60) & (6) & (ิ) \\
\hline ÓTIMO & BOM & NĀO SEI & RUIM & PÉSSIMO \\
\hline
\end{tabular}

Fonte: Elaborado pelas pesquisadoras (2017).

Através de métodos estatísticos descritivos e porcentagem, por se tratar de um número superior a 100 sujeitos, chegou-se ao resultado da visão de mundo em relação à criança negra e a avaliação da mudança de olhar após a intervenção. Os valores encontrados foram expressos através de gráficos para favorecer a visualização. O estudo foi aprovado pelo Comitê de Ética da instituição das pesquisadoras em questão, através da Plataforma Brasil, sob o número 2.298 .444 . 


\section{ANÁLISE DE DADOS E RESULTADOS}

Das 800 crianças que participaram da intervenção na referida instituição educacional da rede pública, 408 alunos responderam o pré e o pós-testes. Nesse processo de tratamento de dados, 14 testes foram descartados por não estarem com todas as questões respondidas e 1 não foi contabilizado por ter mais de uma resposta assinalada. Dessa forma, o universo de dados passou a ser 393 testes, dos quais tem-se os seguintes gráficos e discussões:

Figura 3 - Pré teste - Ser negro é:

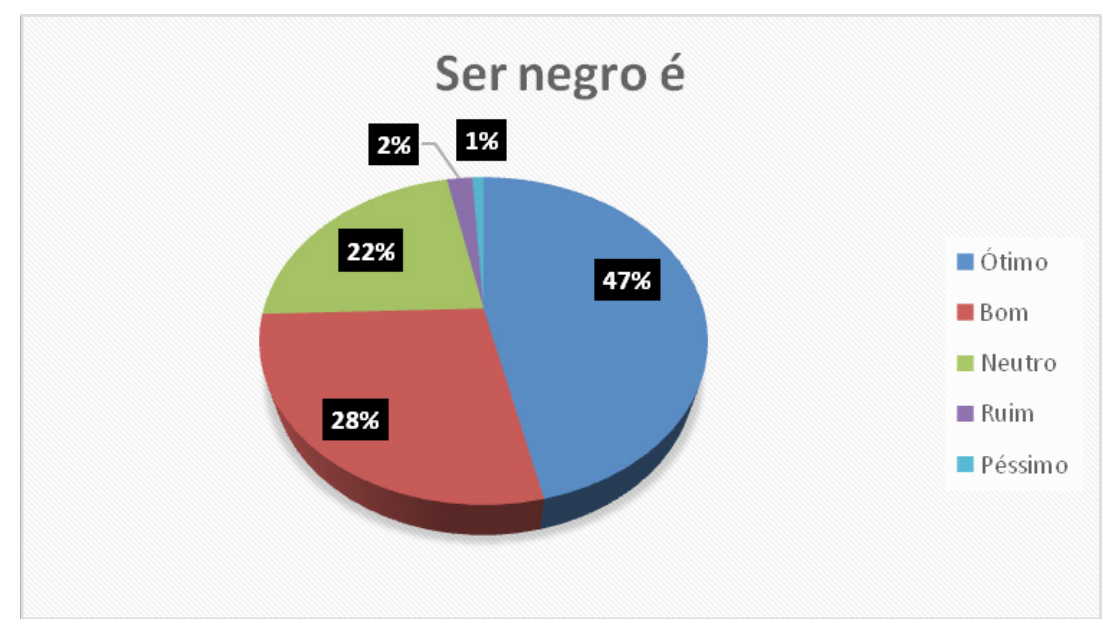

Fonte: Elaborado pelas pesquisadoras com base na pesquisa de campo (2017).

Na Figura 3 identifica-se que $47 \%$ dos respondentes consideram que é ÓTIMO ser negro e, somado à alternativa BOM, com $28 \%$, tem-se um total de $75 \%$ respondendo que ser negro não é negativo. Isso mostra que, provavelmente, a instituição de ensino tem trabalhado em um contexto de valorização do outro e da diversidade étnica. Mas após a intervenção, tem-se os seguintes resultados na Figura 4, que se segue: 
Figura 4 - Pós-teste - Ser negro é:

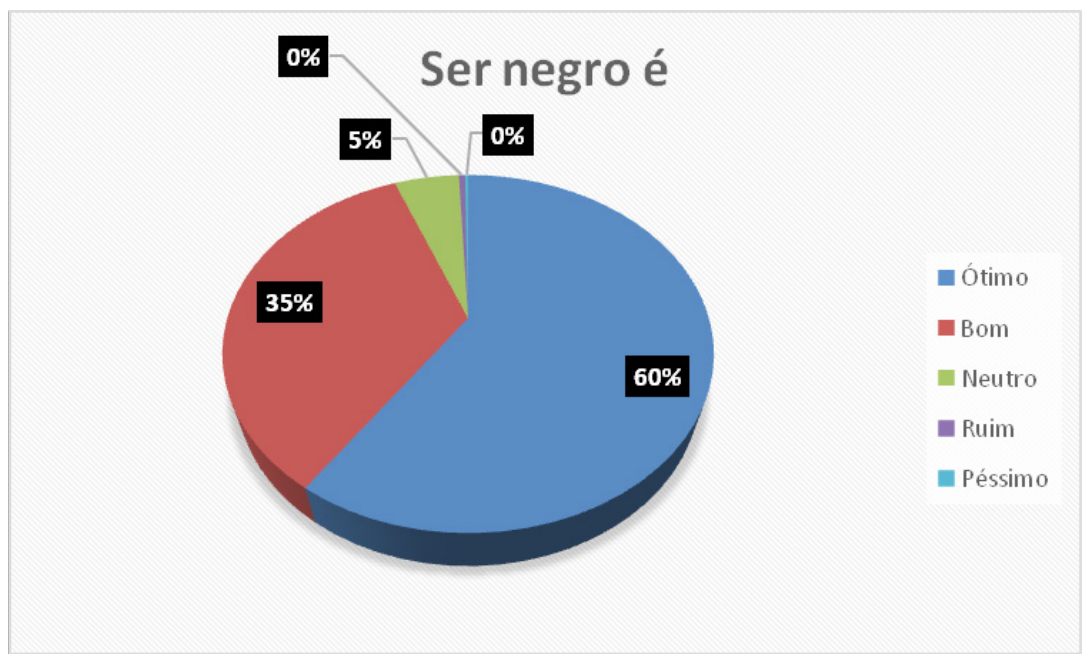

Fonte: Elaborado pelas pesquisadoras a partir da pesquisa de campo (2017).

Ao observar as Figuras 3 e 4, os gráficos sobre o grau de aceitação referente às diferenças raciais, identifica-se que, após a intervenção, houve uma alteração significativa no olhar da criança sobre ser negro. De $47 \%$, o grau ÓTIMO foi para $60 \%$. O grau BOM, de $28 \%$ subiu para $35 \%$, o NEUTRO (não sei) diminuiu de $22 \%$ para $5 \%$ e o péssimo tornou-se inexistente. Percebe-se que projetos sociais e intervenções pedagógicas são valiosos instrumentos para interferir positivamente na visão de mundo da criança negra, confirmando a afirmação de Dias (2012) de que o trabalho pedagógico, ao fazer uso de instrumentos, recursos e intervenções, pode interferir de forma positiva na construção da identidade da criança negra e inclusive na forma como essa criança lê o mundo e se insere nele.

Fúlvia Rosemberg (2005) realça a importância de preparar educadores para lidar com as questões referentes à questão afro-brasileira e como essa discussão reflete no processo de leitura tanto da criança negra quanto do colega não negro acerca do ser negro. Porque há uma hostilidade racial no cotidiano escolar que se encarrega de moldar negativamente a imagem do negro. E Calai (2005), ao afirmar que a leitura do mundo é fundamental para o exercício da cidadania, percebe a necessidade de interferir no processo dessa leitura de mundo das crianças negras, em especial no sentido de fortalecer a autoimagem ao se considerar atuante em um papel importante na sociedade. 
A situação de discriminação em sala de aula deve ser desmistificada, e o professor precisa chamar a atenção dos alunos para essa questão, porque isso interfere na composição da identidade, na representação coletiva, na autoestima dos afro-brasileiros e, por que não reafirmar, na leitura de mundo dessas crianças. Pois o preconceito racial acarreta danos psicológicos e físicos às crianças negras, interferindo na construção da identidade, na leitura de mundo e reafirmando o preconceito e a não aceitação e a não valorização de si mesmo (MUNANGA, 2005; MONTEIRO, 2011).

A segunda questão, contida tanto no pré-teste quanto no pós-teste, refere-se à leitura que a criança faz sobre ter um amigo negro. As Figuras $5 \mathrm{e}$ 6 apontam os resultados:

Figura 5 - Pré-teste - Ter amigo negro é:

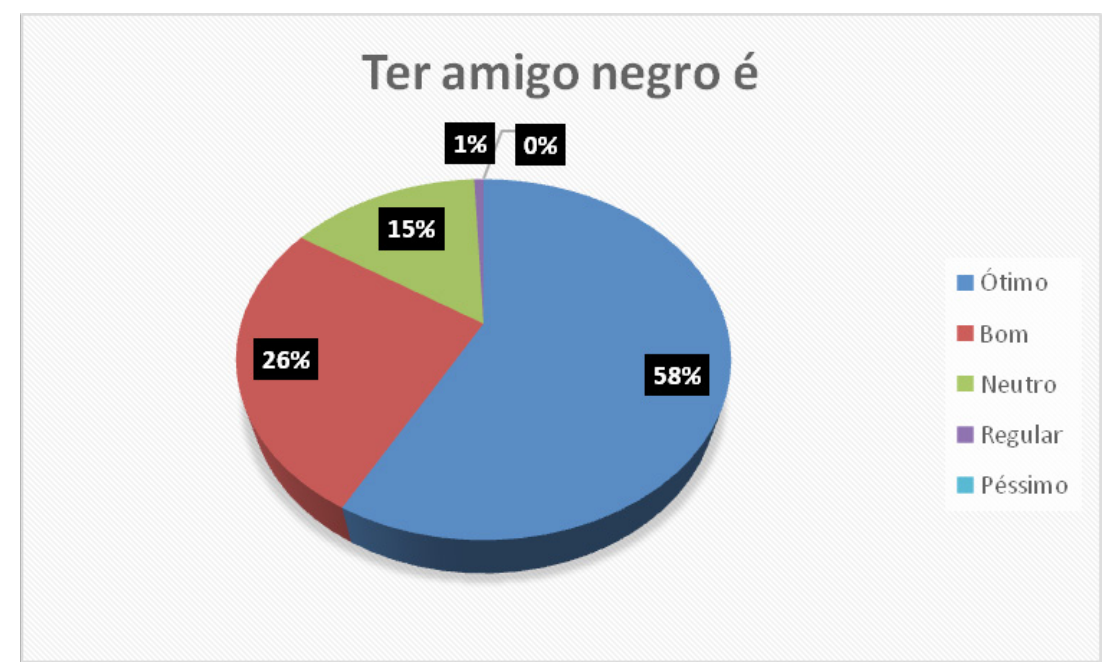

Fonte: Elaborado pelas pesquisadoras a partir da pesquisa de campo (2017).

Observa-se, na Figura 5, que $58 \%$ e $26 \%$ dos respondentes consideram ÓTIMO e BOM, respectivamente, ter um amigo negro. Essas $84 \%$ das crianças que responderam ao teste entendem ser positivo relacionar-se com crianças negras. Essas informações asseveram a ideia de que, provavelmente, sejam trabalhadas em sala de aula as questões da diversidade étnica. 
Figura 6 - Pós Teste - Ter amigo negro é:

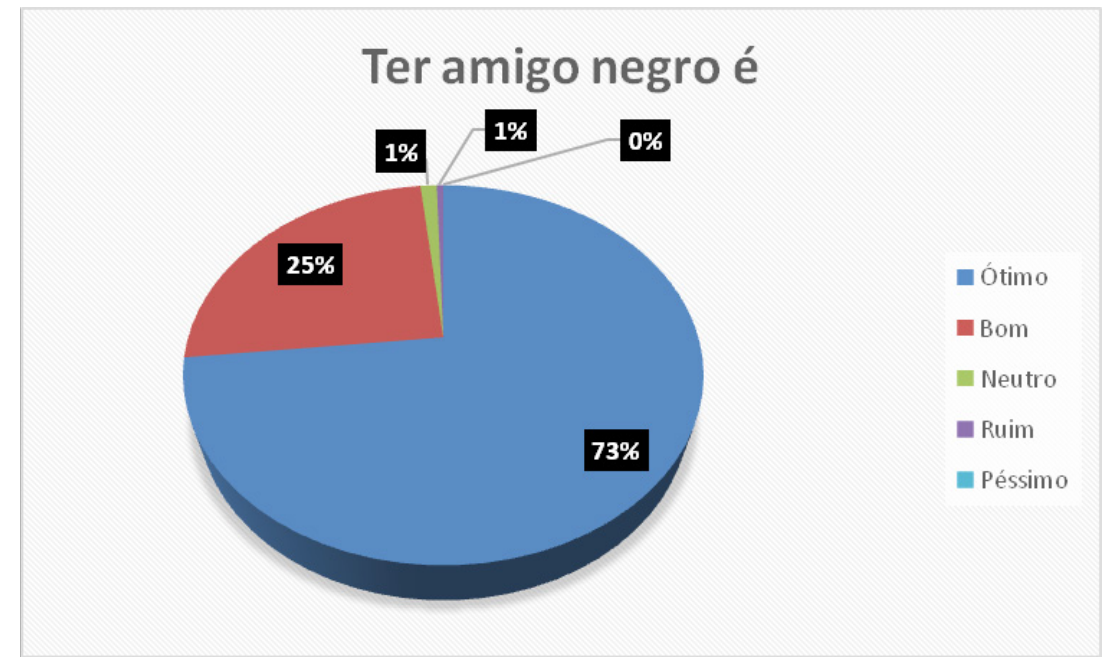

Fonte: Elaborado pelas pesquisadoras a partir da pesquisa de campo (2017).

Os gráficos que mostram as reações das crianças sobre o fato de ter amigos negros apontam que o grau ÓTIMO aumentou de 58\% para $73 \%$, o grau BOM permaneceu estável, de $26 \%$ a $25 \%$, o grau NEUTRO (não sei) diminuiu significativamente de $15 \%$ para $1 \%$, o grau RUIM tornou-se inexistente e o grau PÉSSIMO, de $0 \%$ foi para $1 \%$ - por ter sido uma alteração mínima, não se considera relevante a alteração. Uma variável que pode interferir nessa resposta, além do aspecto racial, são as relações pessoais. Ou seja, caso a criança tenha tido algum atrito com um coleguinha negro, esse ocorrido pode ter sido um motivador de um sentimento de rejeição e generalização no ato da resposta no teste respondido.

Algumas lacunas foram detectadas ao analisar os dados, a saber: algumas crianças não fizeram o pós-teste, as pesquisadoras deveriam ter identificado a etnia do respondente, ao assinalar sobre "Ser negro é" algumas crianças responderam "Não sei" e acrescentaram "Eu não sou negra". Isso mostra que as crianças que marcaram a resposta "Não sei" estavam tentando dizer que elas não sabem como é ser negro porque isso não faz parte da vida delas. Assim mesmo, entende-se que essa variável pode, até certo ponto, afetar os resultados, mas não compromete significativamente as conclusões desta pesquisa.

Algumas alterações específicas são relevantes para observar o olhar da criança sobre ser negro. Nesses casos, o resultado da intervenção acarretou 
um efeito contrário ao previsto. Organizou-se em dois quadros para favorecer a organização e visualização dos dados:

Figura 7 - Ser negro é

\begin{tabular}{|c|c|c|}
\hline \multicolumn{2}{|c|}{ ALTERAÇÃo } & $\begin{array}{c}\text { Quantidade } \\
\text { No absoluto }\end{array}$ \\
\hline Bom & Não Sei & 6 \\
\hline Ótimo & Bom & 13 \\
\hline Ótimo & Ruim & 1 \\
\hline Ótimo & Péssimo & 1 \\
\hline Ótimo & Não sei & 1 \\
\hline
\end{tabular}

Fonte: Elaborado pelas pesquisadoras a partir da pesquisa de campo (2017).

O que se destaca na Figura 7 é a alteração do item BOM para o NÃO SEl, demonstrando, talvez, uma reflexão sobre a autoimagem e dúvida como consequência dessa reflexão. Algumas crianças negras são estereotipadas negativamente no cotidiano e, por conseguinte, isso produz na criança uma imagem desvalorizada de si, colaborando para sua autoexclusão ou uma baixa autoestima. A depreciação de sua imagem afeta o processo de construção de sua identidade e, consequentemente, sua visão de mundo. Essa situação também favorece a construção de convicções que desvalorizam suas características étnicas, reafirmando o preconceito que "é produto da cultura que, em algumas sociedades, transformou-se em arma ideológica para legitimar e justificar a dominação de uns sobre os outros" (MUNANGA, 2005, p.18).

Figura 8 - Ter um amigo negro é

\begin{tabular}{|c|c|c|}
\hline \multicolumn{2}{|c|}{ ALTERAÇÃo } & $\begin{array}{c}\text { Quantidade } \\
\text { No absoluto }\end{array}$ \\
\hline Ótimo & Bom & 17 \\
\hline Bom & Não sei & 1 \\
\hline Ótimo & Ruim & 1 \\
\hline Ótimo & Não sei & 1 \\
\hline Não sei & Não sei & 1 \\
\hline
\end{tabular}

Fonte: Elaborado pelas pesquisadoras a partir da pesquisa de campo (2017). 
Os dados mais significativos nas Figuras 7 e 8 são 13 crianças que, antes da intervenção, afirmaram que ser negro era ÓTIMO e, após a intervenção, mudaram a opinião para BOM. No aspecto de ter amigo negro, 17 crianças alteraram a resposta, de ÓTIMO para BOM. Percebe-se uma variável nesse contexto, o entendimento da diferença entre ÓTIMO e BOM é uma questão a ser investigada em outro momento. Nessa direção, é importante ressaltar que duas crianças escreveram com letras maiúsculas duas frases na margem do teste: "Eu gosto de negro". Mas a sua avaliação mudou após a intervenção, de ÓTIMO para BOM. Esse aspecto ficará como proposta de investigação futura, na qual essas crianças podem ser sujeitos de uma entrevista ou grupo focal, para identificar as causas envolvidas nessa mudança de opinião.

\section{CONCLUSÃo}

O instrumento do professor na educação básica, em sala de aula, como livros e outros materiais didáticos visuais e audiovisuais, traz em seu contexto os mesmos conteúdos viciados, depreciativos e preconceituosos da sociedade. E se faz presente também no cotidiano escolar, nas relações entre aluno-aluno, professor-aluno, etc.

Com base nos dados coletados, a intervenção realizada em uma escola da rede pública, com o intuito de tratar sobre a valorização do ser negro, de forma lúdica, para crianças do ensino fundamental I, mostrou-se válida, no sentido de que as crianças tiveram mudança positiva de opinião. Pois, de $47 \%$, foi para $60 \%$ o total de crianças que assinalaram ser ÓTIMO ser negro após a intervenção. Isso demonstra a influência que tem o espaço escolar de propiciar mudanças por meio de conhecimento, debate e reflexão acerca do preconceito, do estereótipo e da discriminação que permeiam a sociedade brasileira.

Conclui-se, portanto, que as intervenções lúdicas proporcionam reflexão e possibilitam mudanças. E isso pode auxiliar na erradicação de atitudes preconceituosas e estereótipos negativos que existem acerca do ser negro. A visão de mundo e, portanto, a leitura do mundo pode ser redirecionada no sentido de possibilitar questionamentos e a desconstrução de mitos de superioridade e inferioridade entre os indivíduos que foram postos pela cultura racista, na qual foram socializados.

Carone e Bento (2012) dizem que não se podem responsabilizar as pessoas pelo que elas aprendem sobre preconceito e racismo, na família, na escola e nos meios de comunicação. Mas, a partir do momento em que o indivíduo adquiriu maior compreensão sobre esse processo, deve criar 
consciência e responsabilidade e tentar reverter, modificar e interromper esse ciclo de preconceito e mudar seu comportamento.

\section{IMPACT OF A PEDAGOGICAL INTERVENTION ON THE CHILD'S WORLD READING ABOUT BEING BLACK}

ABSTRACT: The objective of this research is to analyze the impact of a pedagogical intervention in the child's world perspection about the blacks. This study is characterized by being qualitative an do fanapplied nature. The world perspective related to the black child wase valuated through the preand post test answer sobtained by the facial scale question naire. The child learn store ad the world, and she begin store ad the world before even reading the letters. This unfolds in a range of interpretations whose values are being for med from the experiences of black children who may bereading the world and in a context whose discriminatory actions in the school are present. It is identified that playful interventions allow for reflection and change, helping to eradicate prejudiced attitudes and negative stereotypes about blackness.

KeYwords: Stereotype. Black child. World vision. Facial ScaleQuestionnaire.

\section{EL INPACTO DE UNA INTERVENCIÓN PEDAGOGICA EN LA LECTURA DE MUNDO DE UN NIÑO SOBRE SER UN NEGRO}

RESUMEN: El objetivo de la presente investigación es analizar el impacto de una intervención pedagógica en la lectura de mundo de un niño sobre ser negro (a). La característica del estudio es cualitativa y de aplicación. La lectura de mundo asociado al niño negro (a), fue evaluado a través de las respuestas de pre e post test, obtenidas por el cuestionario facial. El niño aprende y comienza a leer el mundo, antes de conocer las letras. El desenlace es encontrado en una gama de interpretaciones, cuyos valores se construyen a partir de experiencias que los niños negros vivencian leyendo el mundo en un contexto donde las acciones discriminatorias en el ambiente escolar están presentes. Fue identificado que las intervenciones lúdicas posibilitan reflexión y cambios ayudando en la erradicación de actitudes preconceptuosas y estereotipados negativos que existen al respecto de ser un negro.

Palabras Clave: Estereotipo. Niño negro. Visión de mundo. Cuestionario de escala facial. 


\section{REFERÊNCIAS}

AAKER, D. A. et al. Marketing research. 7th. ed.. New York: John Wiley \& Sons, 2001.

ANDRADE, L. B. P. Educação infantil: discurso, legislação e práticas institucionais [online]. São Paulo: Editora UNESP; Cultura Acadêmica, 2010.

BENTO, M. A. S. Educação infantil, igualdade racial e diversidade. São Paulo: Centro de Estudo das Relações de trabalho de Desigualdade (CEERT), 2011.

BONATE L. P. Analysis of pretest-posttest designs. USA.: Chapman Hall/CRC, 2000.

BORGES JUNIOR, C. Alfabetização: Leitura do mundo, leitura da palavra. Educar em Revista, Curitiba, Brasil, n. 57, p. 303-310, jul./set. 2015. Disponível em: <https://revistas. ufpr.br/educar/article/view/41996>. Acesso em: 9 nov. 2017.

BRASIL. Diretrizes Curriculares Nacionais para a educação das relações étnico-raciais e para o ensino de história e cultura afro-brasileira e africana. Brasília: MEC, 2004.

CALAI, H. C. Aprendendo a ler o mundo: a geografia nos anos iniciais do ensino fundamental. Cad. Cedes, Campinas, v. 25, n. 66, p. 227-247, maio/ago. 2005.

CARONE, I.; BENTO, M. Psicologia social do racismo: estudos sobre branquitude e branqueamento no Brasil. 5. ed. Petrópolis, RJ: Vozes, 2012.

CAVALLEIRO, E. Do silêncio do lar ao silêncio escolar: racismo, preconceito e discriminação na educação infantil. São Paulo: Editora Contexto, 2012.

DIAS, L. R. Aspectos políticos, jurídicos conceituais. In: BENTO, M. A. S. Educação infantil, igualdade racial e diversidade. São Paulo: Centro de Estudo das Relações de Trabalho de Desigualdade (CEERT), 2012.

GOFFMAN, E. Estigma: notas sobre a manipulação da identidade deteriorada. Tradução de Márcia Bandeira de Mello Leite Nunes. 4. ed. Rio de Janeiro: Livros Técnicos e Científicos, 2015.

GOMES, J. V. Família popular: Mito ou estigma? Travessia, socialização primária: tarefa familiar? Cadernos de Pesquisa, São Paulo, n. 91, p. 54-61, 1994.

GOMES, N. L. Educação e Identidade negra. Belo Horizonte: POSLIT/CEL, Faculdade de Letras da UFMG, 2002. (v. 6).

LOUREIRO, A. M. A. O ensino de música na escola fundamental: um estudo exploratório. 2001. 241 f. Dissertação (Mestrado em Educação) - Pontifícia Universidade Católica de Minas Gerais, Belo Horizonte, 2001.

MELO, Z. M. Os estigmas: a deterioração da identidade social. PUC-MG, 2000. Disponível em: <http://www.sociedadeinclusiva.pucminas.br/anaispdf/estigmas.pdf>.

MIRANDA, M, A.; MARTINS, M. S. Maternagem: quando o bebê pede colo. 2. ed. São Paulo: Terceira Margem, 2009. 
MONTEIRO, E. S. Construção da identidade no contexto sociocultural dos sujeitos. Revista Fórum Identidades, v. 10, p. 49-62, 2011.

MUNANGA, K; GOMES, N. L. O negro no Brasil de hoje. São Paulo: Global, 2016.

MUNANGA, K. Superando o racismo na escola. Brasília: Ministério da Educação, Secretaria de Educação Continuada, Alfabetização e Diversidade, 2005.

. Negritude: usos e sentidos. São Paulo: Autêntica,2012.

RAMALHO, G. Utilização de modelos lineares em designs pré-teste e pós-teste Grupo único e experimental versus controlo. Aná. Psicológica, Lisboa, v. 15, n. 1, p. 5-17, mar. 1997. Disponível em: <http://www.scielo.mec.pt/scielo.php?script=sci_ arttext\&pid=S0870-82311997000100002\&lng=pt\&nrm=iso >. Acesso em: 9 nov. 2017.

ROSEMBERG, F. Desigualdade de raça e gênero no sistema educacional brasileiro. In: SEMINÁRIO INTERNACIONAL AÇÕES AFIRMATIVAS NAS POLÍTICAS EDUCACIONAIS BRASILEIRAS: O CONTEXTO PÓS DURBAN. Anais.. Brasília: Diversidade Educação Infantil, 2005. p. 10-55

TELES, C. P. Linguagem escolar e a construção da identidade racial da criança negra na educação infantil. Revista Anagrama, ano 1, ed. 4, jun./ago. 2008.

VALLE, L. E. R.; GUZZO, R. S. L. Desenvolvimento infantil. Ribeirão Preto, SP:Tecmed, 2004.

Germana Ponce de Leon Ramírez: Doutorado em Geografia Humana pela Universidade Federal de Santa Catarina (2011). Mestrado em Geografia Humana pela Universidade Federal de Santa Catarina (2003). Graduação em Geografia pela Universidade Federal da Paraíba (1999). Titular no ensino superior no UNASP (EC); professora permanente no Mestrado Profissional em Educação no UNASP (EC). Atuando, principalmente, no campo do conhecimento da geografia humana, com enfoque sobre a diversidade étnica e cultural brasileira (questão indígena e afrobrasileira).

E-mail:sermana.ramirez@unasp.edu.br 
Luciane Weber Bala Hees: Doutora em Psicologia da Educação na PUC - SP na área de formação de professores. Mestre em Educação, especialista em Supervisão Escolar e Docência Universitária e graduada em Pedagogia pelo Centro Universitário Adventista de São Paulo (1992). Exerceu a função de Coordenadora Pedagógica, Administradora Escolar e Orientadora Educacional na Educação Básica, assim como coordenou o Curso de Pós-Graduação em Docência Universitária $e$ as atividades de estágio do Curso de Pedagogia. Exerce a função de Professora Colaboradora do Curso de Mestrado do UNASP - EC, Professora Titular do Ensino Superior do Centro Universitário Adventista de São Paulo. Tem experiência na área de Educação, com ênfase em Gestão Escolar, Pedagogia Empresarial e Hospitalar, Psicologia da Educação, Formação Docente, Organização das Práticas Pedagógicas, Avaliação Educacional e Planejamentos Educacionais, atuando principalmente nos seguintes temas: coordenação pedagósica, formação $e$ prática do professor.

E-mail: luciane.hees@gmail.com 